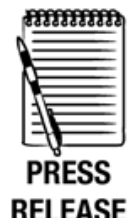

RELEASE

\title{
Risk and protective factors associated with gang affiliation among high-risk youth: a public health approach
}

\author{
Dawn Delfin McDaniel
}

- An additional appendix is published online only. To view this file please visit the journal online (http://injuryprevention. bmj.com/content/18/4.toc).

\section{Correspondence to}

Dr Dawn D McDaniel, Epidemic Intelligence Service Officer assigned to the Division of Violence Prevention, National Center for Injury Prevention and Control, Centers for Disease Control and Prevention, 4770 Buford Hwy NE, MS F64, Atlanta, GA 30341, USA: dawn.mcdaniel@cdc.hhs.gov

The findings and conclusions in this manuscript are those of the author and do not necessarily represent the views of the Centers for Disease Control and Prevention/the Agency for Toxic Substances and Disease Registry.

Accepted 8 October 2011 Published Online First 11 January 2012

\section{(2) UN LCKK:}

This paper is freely available online under the BMJ Journals unlocked scheme, see http:// injuryprevention.bmj.com/site/ about/unlocked.xhtml

\begin{abstract}
Background Gang violence accounted for $20 \%$ of homicides in large cities from 2002 to 2006. Preventing gang affiliation (ie, youth who either desire or have gang membership) might reduce subsequent gang activity. Previous research has focused on identifying risk factors for gang affiliation; however, little information is available on protective factors.
\end{abstract}

Aim To identify risk and protective factors to provide more direction for gang violence prevention strategies. Methods The author analysed cross-sectional survey data from 4131 youths in grades 7, 9, 11 and 12. Data were collected in 2004 from students in a high-risk, urban public school district. Regression analyses were conducted to assess the association between gang affiliation and alcohol and drug use, delinquency, depressed mood, suicidal ideation, peer victimisation, parental monitoring and positive reinforcement, adult, family and peer support, coping skills, and school connectedness. Analyses were controlled for sex, race/ ethnicity and age.

Results An estimated 7\% of youths were gang affiliated. Adjusting for all factors, gang affiliation was positively associated with engaging in any delinquent behaviours (prevalence OR: 2.07; 95\% Cl 1.18 to 3.64), frequent alcohol use (OR: 2.62; $95 \% \mathrm{Cl} 1.85$ to 3.72 ) and frequent drug use (OR: $1.95 ; 95 \% \mathrm{Cl} 1.15$ to 3.29 ). Gang affiliation was negatively associated with moderate levels of parental monitoring (OR: $0.67 ; 95 \% \mathrm{Cl} 0.54$ to 0.85 ) and coping skills (OR: $0.54 ; 95 \% \mathrm{Cl} 0.42$ to 0.71 ).

Conclusions The findings suggest the potential benefit of increasing parental monitoring and coping skills and reducing delinquency, alcohol use and drug use to prevent gang affiliation.

\section{INTRODUCTION}

From 2002 to 2006, gangs were responsible for approximately $20 \%$ of homicides in the 88 largest US cities, ${ }^{1}$ and gang violence has been perceived as reaching 'epidemic' levels in many urban areas. ${ }^{2}$ Furthermore, gang members are more likely than their non-gang-affiliated peers to engage in crime and violence, ${ }^{3}{ }^{4}$ which increases their risk of violence-related injuries and death. ${ }^{56}$ While only an estimated $5 \%$ of the US population has ever joined a gang, ${ }^{7}$ gang membership has reached $14-30 \%$ of the population in many urban areas. ${ }^{89}$ The impact of gang membership on a youth's health is tremendous and preventing gang membership or the desire for gang affiliation early in adolescence might significantly reduce subsequent gang-related violence. This study explores a public health approach to understanding the factors that increase risk for, as well as protect against, gang affiliation among youth who reside in a high-risk community (ie, a community with high levels of serious crime, poverty and unemployment).

Traditionally, initiatives designed to reduce gang affiliation have not focused on primary prevention strategies; that is, strategies aimed at preventing gang affiliation before gangs begin recruiting youth. These strategies often attempt to prevent factors that might increase risk of gang affiliation while promoting factors that might lower risk. Risk factors for gang affiliation include friendships with delinquent peers, lack of parental monitoring, negative life events (eg, loss of parent), and positive attitudes towards delinquency or engaging in delinquency (eg, violence perpetration). ${ }^{7} 10$ Other risky behaviours associated with gang affiliation include alcohol use and drug use. ${ }^{11}$ To date, little research has focused on mental health related factors, such as depression and suicidal ideation; ${ }^{11}$ these factors might be important since they are common among youth who engage in delinquency. ${ }^{12}$ Several studies have also shown that the probability of gang affiliation increases as risk factors accumulate. ${ }^{10} 11$

In contrast to the amount of literature on risk factors for gang affiliation, the literature on protective factors is limited. (The term 'protective factor' often refers to a factor that buffers the effects of risk. However, for this study, the term refers to factors found to be negatively associated with gang affiliation.) The few studies that have embarked on this topic have, in general, found that youth who have strong social skills, a supportive family (eg, parental monitoring, warmth and control) and connections with religion/religious institutions are less likely to seek gang affiliation than their peers ${ }^{13-15}$; however, more research is still needed to understand the protective factors for youth in high-risk communities, especially with regard to understudied factors, such as positive peer support and school commitment. ${ }^{16}$ This study assesses risk and protective factors associated with gang affiliation among a high-risk youth population to better inform primary prevention strategies.

\section{METHODS \\ Study design}

This study used data provided by the Centers for Disease Control and Prevention's 'Youth Violence Survey: Linkages among Different Forms of Violence' study. ${ }^{17}$ The Youth Violence Survey was a cross-sectional study of youth in a high-risk community that examined various types of 
violence and their common risk and protective factors. These factors addressed the different domains of the social-ecological model, which includes individual, peer, family and community level factors. ${ }^{18}$ This survey also captured information on gang affiliation.

\section{Study population}

The Youth Violence Survey was administered to students in grades 7, 9, 11 and 12 in a high-risk community. The high-risk community was identified using multiple indicators of risk (ie, nationally the school district was among the highest 25 in poverty, the highest 15 in single-parent families, the highest 10 in serious crime rates and the highest 35 in rate of unemployment). This site was selected based on these demographic characteristics and pragmatic considerations (eg, commitment to study and feasibility of obtaining adequate census of students in targeted grades). While the site will not be named to protect its confidentiality, the community was racially and ethnically diverse with a population of less than 250000 . There were 16 public schools within this community's school district and all schools participated.

The study received Institutional Review Board approval from the Centers for Disease Control and Prevention and ORC Macro International. Prior to data collection, written parental consent and student assent were obtained from all students: $14 \%$ of students did not return the consent form and $1 \%$ of students refused to participate. Non-English speaking parents were offered consent forms in the major languages represented in the community, including Spanish.

Data collection for this study was undertaken in April 2004. Students voluntarily completed the anonymous self-administered 174-item questionnaire during one class period. Students received a $\$ 5$ gift card for returning the parental permission form (regardless of whether parental permission was granted) and another $\$ 5$ gift card after completing the survey. Those students who did not want to participate were assigned individual deskwork by their teacher. Among the 5098 students who met eligibility for the study, a total of 4131 (81\%) chose to participate: 1491 students were in grade 7 (83\% participation rate), 1117 students were in grade 9 (73.4\% participation rate) and 1523 students were in grades 11 and 12 (79\% participation rate). Further information about the study design, the population and the setting is available in the study by Swahn et al. ${ }^{17}$

\section{Measures}

\section{Outcome variable}

The outcome variable for this study, gang affiliation, was based on one item in which students were asked how they felt about joining a gang. The students were not given clarification regarding the definition of a gang. Responses were dichotomised to distinguish between gang-affiliated students who reported either the desire to join a gang or have an active gang membership with no intention of leaving the gang and nongang-affiliated students who reported no desire to join or actively participate in a gang.

\section{Main explanatory variables of interest}

Thirteen variables were examined to identify their association with gang affiliation. These variables spanned the domains of individual, peer, family and community level characteristics. Six factors were assessed to determine whether they had a positive association (ie, act as potential risk factors). These factors included having a depressed mood in the past 30 days, having suicidal ideation in the past year, having consumed alcohol at least once in the past year, having used drugs at least once in the past year, engaging in any delinquent behaviour in the past year and having been victimised in the past year. Seven variables were assessed to determine whether they had a negative association with the outcome variable (ie, act as potential protective factors). These variables included having the confidence to cope with conflict, having peer support, having parents who have used positive reinforcement in the past 30 days, having parents who have used monitoring strategies in the past 30 days, having family support, having adult support at school and feeling connected to school.

Details of how these variables were coded from the survey are shown in the online supplementary appendix A. In general, these variables exhibited high internal consistency (see Logan et al for further description $\left.{ }^{19}\right)$. Multi-item variables were re-classified to account for the distribution of the data in a conservative manner while retaining variability when possible.

\section{Statistical analysis}

Basic descriptive analyses were conducted to characterise nongang- and gang-affiliated students. Logistic regression was used to assess crude associations between the outcome variable and demographic variables as well as the main variables of interest. Associations were reported via prevalence ORs. Robust variance estimates were used to account for potential effects from cluster correlation within each school. Multiple logistic regression was used to determine the adjusted ORs for each of the main variables of interest. This model adjusted for demographic factors (ie, age, sex and race/ethnicity) to control for potential developmental and sociocultural influences. ${ }^{20}$ Since youths can have more than one risk or protective factor, we also adjusted for all of these factors in the model to provide more accurate individual associations between the factors and the outcome variable. Furthermore, we assessed for colinearity using variable inflation factor scores. Variable inflation factor scores fell within acceptable ranges $(<2)$, which suggests that colinearity among the variables used in the models was not an issue.

The proposed risk and protective factors were summed to create cumulative indices. For these indices, all variables were rendered dichotomous (see online supplementary appendix A for more details). Multiple logistic regressions were used to determine the association of these indices with gang affiliation, controlling for age, sex and race/ethnicity. Also, the cumulative risk index was dichotomised into a risk grouping variable by a median split to distinguish those at high risk ( $\geq 3$ risk factors) from those at low risk ( $\leq 2$ risk factors) for subsequent analyses. This variable was used in a model that included interaction terms between this risk grouping variable and the salient protective factors from the adjusted model.

To illustrate the potential benefit of having the salient protective factors at high and low levels of risk, another multiple logistic regression was run including the risk grouping variable and key protective factors. The estimated predicted probabilities for gang affiliation were determined for youth at high and low risk with no protective factors and with each combination of protective factors. Fisher's exact tests with a Bonferroni correction for multiple comparisons were used to compare these probabilities.

\section{RESULTS}

Descriptive characteristics of the study population are reported in table 1. The majority of this youth population was female, of ethnic minority status and of high school age (ie, 14-18 years or older). An estimated $7.1 \%$ of the youths were gang 
Table 1 Frequencies and crude ORs for demographic, risk and protective factors for gang affiliation ( $\mathrm{N}=4131$ )

\begin{tabular}{|c|c|c|c|}
\hline \multirow[b]{2}{*}{ Variable } & \multirow[b]{2}{*}{ Total N (\%) } & \multicolumn{2}{|c|}{$\begin{array}{l}\text { Gang-affiliated students } \\
(\mathrm{N}=294)\end{array}$} \\
\hline & & $\mathbf{N}(\%)$ & Crude OR (95\% CI) \\
\hline \multicolumn{4}{|l|}{ Demographic factors } \\
\hline \multicolumn{4}{|l|}{ Age } \\
\hline $12-13$ years & $1222(29.58)$ & $95(7.77)$ & Referent \\
\hline $14-15$ years & $1180(28.56)$ & $105(8.90)$ & $1.16(0.72$ to 1.88$)$ \\
\hline 16 years or older & 1705 (41.27) & $92(5.40)$ & $0.68(0.38$ to 1.22$)$ \\
\hline Missing & $24(0.58)$ & 2 (8.33) & $1.08(0.25$ to 4.62$)$ \\
\hline \multicolumn{4}{|l|}{ Sex } \\
\hline Female & $2127(51.49)$ & $113(5.31)$ & Referent \\
\hline Male & $1982(47.98)$ & $179(9.03)$ & 1.77 (1.37 to 2.28$)$ \\
\hline Missing & $22(0.53)$ & $2(9.09)$ & $1.78(0.38$ to 8.47$)$ \\
\hline \multicolumn{4}{|l|}{ Race/ethnicity } \\
\hline White, non-Hispanic & $922(22.32)$ & $43(4.66)$ & Referent \\
\hline $\begin{array}{l}\text { African American, } \\
\text { non-Hispanic }\end{array}$ & $935(22.63)$ & $88(9.41)$ & 2.12 (1.21 to 3.73$)$ \\
\hline Hispanic & 1809 (43.79) & $128(7.08)$ & $1.56(1.05$ to 2.31$)$ \\
\hline Others, non-Hispanic & 416 (10.07) & $33(7.93)$ & 1.76 (1.08 to 2.86$)$ \\
\hline Missing & $49(1.19)$ & 2 (4.08) & $0.87(0.21$ to 3.57$)$ \\
\hline \multicolumn{4}{|l|}{ Potential risk factors } \\
\hline \multicolumn{4}{|l|}{ Depressed mood $†$} \\
\hline No & $2464(59.65)$ & $154(6.25)$ & Referent \\
\hline Yes & $1667(40.35)$ & $140(8.40)$ & $1.43(1.07$ to 1.92$)$ \\
\hline \multicolumn{4}{|l|}{ Suicidal ideation } \\
\hline No & $3416(82.69)$ & $210(6.15)$ & Referent \\
\hline Yes & 715 (17.31) & $84(11.75)$ & 2.03 (1.62 to 2.55$)$ \\
\hline \multicolumn{4}{|l|}{ Alcohol use } \\
\hline Never & $2009(48.63)$ & $81(4.03)$ & Referent \\
\hline $\begin{array}{l}\text { Once a year to } \\
\text { once a month }\end{array}$ & $1273(30.82)$ & $83(6.52)$ & 1.66 (1.11 to 2.47$)$ \\
\hline $2-3$ days a month & $328(7.94)$ & $35(10.67)$ & 2.84 (1.76 to 4.58$)$ \\
\hline $\begin{array}{l}1-2 \text { days a week } \\
\text { or more }\end{array}$ & $391(9.47)$ & $84(21.48)$ & 6.51 (4.64 to 9.15$)$ \\
\hline Missing & $130(3.15)$ & $11(8.46)$ & $2.20(0.88$ to 5.52$)$ \\
\hline \multicolumn{4}{|l|}{ Drug use } \\
\hline Never & $3090(74.80)$ & $139(4.50)$ & Referent \\
\hline $\begin{array}{l}\text { Once a year to } \\
\text { once a month }\end{array}$ & $409(9.90)$ & $41(10.02)$ & $2.37(1.50$ to 3.74$)$ \\
\hline $2-3$ days a month & $130(3.15)$ & $17(13.08)$ & $3.19(1.84$ to 5.56$)$ \\
\hline $\begin{array}{l}1-2 \text { days a week } \\
\text { or more }\end{array}$ & $409(9.90)$ & $84(20.54)$ & 5.49 (3.68 to 8.17$)$ \\
\hline Missing & $93(2.25)$ & $13(13.98)$ & 3.45 (1.79 to 6.64$)$ \\
\hline \multicolumn{4}{|l|}{ Delinquency } \\
\hline Never & $1503(36.38)$ & $29(1.93)$ & Referent \\
\hline $1-3$ times & $1478(35.78)$ & $80(5.41)$ & 2.91 (1.53 to 5.52$)$ \\
\hline $4-9$ times & 447 (10.82) & $56(12.53)$ & $7.28(4.38$ to 12.10$)$ \\
\hline 10 or more times & $645(15.61)$ & 127 (19.69) & 12.46 (7.38 to 21.05$)$ \\
\hline Missing & $58(1.40)$ & $2(3.48)$ & $1.82(0.40$ to 8.17$)$ \\
\hline \multicolumn{4}{|l|}{ Peer victimisation } \\
\hline No & $1880(45.51)$ & $114(7.45)$ & Referent \\
\hline Yes & $2251(54.49)$ & $180(8.00)$ & $1.35(1.04$ to 1.74$)$ \\
\hline \multicolumn{4}{|l|}{ Potential protective factors } \\
\hline \multicolumn{4}{|l|}{ Coping skills } \\
\hline $\begin{array}{l}\text { Low level } \\
\text { of confidence }\end{array}$ & $1475(35.71)$ & $197(13.36)$ & Referent \\
\hline $\begin{array}{l}\text { Moderate level } \\
\text { of confidence }\end{array}$ & $1472(35.63)$ & $75(5.10)$ & $0.35(0.27$ to 0.44$)$ \\
\hline $\begin{array}{l}\text { High level } \\
\text { of confidence }\end{array}$ & $1184(28.66)$ & $22(1.86)$ & $0.12(0.08$ to 0.19$)$ \\
\hline \multicolumn{4}{|l|}{ Peer support } \\
\hline No & $2050(49.62)$ & $173(8.44)$ & Referent \\
\hline Yes & $2081(50.38)$ & $121(5.81)$ & $0.67(0.52$ to 0.86$)$ \\
\hline
\end{tabular}

Continued
Table 1 Continued

\begin{tabular}{|c|c|c|c|}
\hline \multirow[b]{2}{*}{ Variable } & \multirow[b]{2}{*}{ Total N (\%) } & \multicolumn{2}{|c|}{$\begin{array}{l}\text { Gang-affiliated students } \\
(\mathrm{N}=294)\end{array}$} \\
\hline & & $\mathbf{N}(\%)$ & Crude OR $(95 \% \mathrm{Cl})$ \\
\hline \multicolumn{4}{|c|}{ Parental positive reinforcement } \\
\hline No & $1527(36.96)$ & $130(8.51)$ & Referent \\
\hline Yes & $2604(63.04)$ & $164(6.30)$ & 0.72 (0.56 to 0.93$)$ \\
\hline \multicolumn{4}{|l|}{ Parental monitoring } \\
\hline Low level & $1480(35.83)$ & 175 (11.82) & Referent \\
\hline Moderate level & $1332(32.24)$ & $75(5.63)$ & $0.44(0.36$ to 0.55$)$ \\
\hline High level & $1319(31.93)$ & $44(3.34)$ & $0.26(0.20$ to 0.33$)$ \\
\hline \multicolumn{4}{|l|}{ Family support } \\
\hline No & $1823(44.13)$ & $173(9.49)$ & Referent \\
\hline Yes & $2308(55.87)$ & $121(5.24)$ & $0.53(0.41$ to 0.68$)$ \\
\hline \multicolumn{4}{|c|}{ Adult support at school } \\
\hline No & $268(6.49)$ & $33(12.31)$ & Referent \\
\hline Yes & $3863(93.51)$ & $261(6.76)$ & $0.52(0.28$ to 0.96$)$ \\
\hline \multicolumn{4}{|c|}{ School connectedness } \\
\hline No & 867 (20.99) & 75 (8.65) & Referent \\
\hline Yes & $3264(79.01)$ & $219(6.71)$ & $0.76(0.62$ to 0.92$)$ \\
\hline
\end{tabular}

tThe missing response category was added to the referent group for all dichotomous variables and variables divided by tertiles.

affiliated: $2.4 \%$ of the youths reported the desire to join a gang and $4.8 \%$ of the youths reported active gang membership with no intention of leaving the gang. A majority also reported having consumed alcohol in the past 12 months (48.2\%), having participated in delinquent behaviour in the past 12 months $(62.2 \%)$ and having been victimised by a peer in the past 12 months $(54.5 \%)$. However, a large proportion of the study population also reported having at least a moderate level of confidence to cope with conflict $(64.3 \%)$, having parents who have provided positive reinforcement in the past 30 days $(63 \%)$, having parents who monitored their activities at least at a moderate level in the past 30 days (64.2\%), having adult support at school (93.5\%) and feeling connected to school (79\%).

The crude associations between the predictor variables and the outcome variable in table 1 revealed that gang affiliation was most common among youth of ethnic minority status, males, those who had a depressed mood, reported suicidal ideation, used alcohol or drugs, were delinquent, and had experienced peer victimisation. Gang affiliation was least common among youth who had confidence in their coping skills, peer support, parental positive reinforcement, parental monitoring, family support, adult support at school and school connectedness.

The adjusted ORs for all predictor variables are presented in table 2. Alcohol use that occurs at least 2-3 days a month, drug use that occurs at least 1-2 days a week and any delinquency remained positively associated with gang affiliation. Having at least a moderate level of confidence with regard to coping with conflict and having at least a moderate level of parental monitoring remained negatively associated with gang affiliation.

The findings on cumulative risk and protective factor indices are presented in table 3 . Over half of the study population reported two or more risk factors. Those youths with four or more risk factors were nearly six times more likely to be gang affiliated than those with zero to one risk factor. Also, those with three or less protective factors were 5.6 times as likely to be gang affiliated than those who had four or more protective factors reported. The cumulative risk and protective factor indices were analysed in an adjusted model, controlling for demographic characteristics. The odds of gang affiliation were 
Table 2 Adjusted ORs and 95\% Cls for demographic, risk and protective factors for gang affiliation $(\mathrm{N}=4131)$

\begin{tabular}{|c|c|}
\hline Variable & Adjusted OR (95\% CI) \\
\hline \multicolumn{2}{|l|}{ Demographic factors } \\
\hline \multicolumn{2}{|l|}{ Age $†$} \\
\hline $12-13$ years & Referent \\
\hline $14-15$ years & $0.89(0.59$ to 1.34$)$ \\
\hline 16 years or older & $0.45(0.29$ to 0.71$)$ \\
\hline \multicolumn{2}{|l|}{ Sex } \\
\hline Female & Referent \\
\hline Male & $1.35(1.00$ to 1.82$)$ \\
\hline \multicolumn{2}{|l|}{ Race/ethnicity } \\
\hline White, non-Hispanic & Referent \\
\hline African American, non-Hispanic & 2.37 (1.51 to 3.70$)$ \\
\hline Hispanic & $1.45(1.09$ to 1.91$)$ \\
\hline Others, non-Hispanic & $1.79(1.14$ to 2.80$)$ \\
\hline \multicolumn{2}{|l|}{ Potential risk factors } \\
\hline \multicolumn{2}{|l|}{ Depressed mood } \\
\hline No & Referent \\
\hline Yes & $1.20(0.87$ to 1.65$)$ \\
\hline \multicolumn{2}{|l|}{ Suicidal ideation } \\
\hline No & Referent \\
\hline Yes & $1.39(0.93$ to 2.08$)$ \\
\hline \multicolumn{2}{|l|}{ Alcohol use } \\
\hline Never & Referent \\
\hline Once a year to once a month & $1.15(0.80$ to 1.64$)$ \\
\hline $2-3$ days a month & $1.48(1.04$ to 2.13$)$ \\
\hline $1-2$ days a week or more & $2.62(1.85$ to 3.72$)$ \\
\hline \multicolumn{2}{|l|}{ Drug use } \\
\hline Never & Referent \\
\hline Once a year to once a month & $1.57(0.98$ to 2.51$)$ \\
\hline $2-3$ days a month & $1.67(0.94$ to 2.97$)$ \\
\hline $1-2$ days a week or more & 1.95 (1.15 to 3.29$)$ \\
\hline \multicolumn{2}{|l|}{ Delinquency } \\
\hline Never & Referent \\
\hline $1-3$ times & 2.07 (1.18 to 3.64$)$ \\
\hline $4-9$ times & $3.36(1.88$ to 6.02$)$ \\
\hline 10 or more times & $5.10(3.20$ to 8.11$)$ \\
\hline \multicolumn{2}{|l|}{ Peer victimisation } \\
\hline No & Referent \\
\hline Yes & $1.07(0.81$ to 1.41$)$ \\
\hline \multicolumn{2}{|l|}{ Potential protective factors } \\
\hline \multicolumn{2}{|l|}{ Coping skills } \\
\hline Low level of confidence & Referent \\
\hline Moderate level of confidence & $0.54(0.42$ to 0.71$)$ \\
\hline High level of confidence & $0.30(0.19$ to 0.47$)$ \\
\hline \multicolumn{2}{|l|}{ Peer support } \\
\hline No & Referent \\
\hline Yes & $1.03(0.75$ to 1.40$)$ \\
\hline \multicolumn{2}{|l|}{ Parental positive reinforcement } \\
\hline No & Referent \\
\hline Yes & $1.08(0.87$ to 1.34$)$ \\
\hline \multicolumn{2}{|l|}{ Parental monitoring } \\
\hline Low level & Referent \\
\hline Moderate level & $0.67(0.54$ to 0.85$)$ \\
\hline High level & $0.61(0.43$ to 0.86$)$ \\
\hline \multicolumn{2}{|l|}{ Family support } \\
\hline No & Referent \\
\hline Yes & $0.82(0.57$ to 1.17$)$ \\
\hline
\end{tabular}

Continued

significantly higher as a youth accumulated more than two risk factors; however, as the youth acquired over five protective factors the odds of being affiliated with a gang was significantly lowered. No significant associations were found for the inter-
Table 2 Continued

\begin{tabular}{ll}
\hline Variable & Adjusted OR (95\% CI) \\
\hline Adult support at school & \\
No & Referent \\
Yes & $0.74(0.40$ to 1.37$)$ \\
School connectedness & \\
No & Referent \\
Yes & $1.15(0.91$ to 1.46$)$ \\
\hline The model was adjusted for all demographic factors, potential risk factors and potential \\
protective factors. \\
†The missing response category was added to the referent group for all variables.
\end{tabular}

action terms between risk level and the significant protective factors, suggesting that these protective factors did not buffer risk. Instead, the protective factors had a similar negative association with gang affiliation for all youth regardless of risk level.

The predicted probabilities for gang affiliation based on various combinations of the significant protective factors (ie, confidence in coping skills and parental monitoring) and risk level are presented in table 4. Youth who reported having either coping skills alone or coping skills in combination with parental monitoring had a significantly lower probability for gang affiliation than those youth with neither protective factor, regardless of risk level $(\mathrm{p}<0.01)$. Also, youth who were considered high risk with both protective factors had significantly lower probabilities for gang affiliation than youth at low risk who did not have either protective factor $(p<0.05)$. Youth at high risk with coping skills alone had similar probabilities for gang affiliation as youth at low risk with neither protective factor.

\section{DISCUSSION}

The finding that gang affiliation is associated with engaging in delinquent activities, particularly illicit alcohol and drug use, is one of the most consistent findings in the gang literature. ${ }^{4} 11$ While the temporal relationship of these variables cannot be explained using the current study design, prior research using longitudinal data has shown that delinquency and illicit substance use have an 'enhancing' relationship with gang affiliation. ${ }^{11}$ For example, it has been found that early involvement in these antisocial behaviours elevates the risk for subsequent gang

Table 3 Frequencies and adjusted ORs for cumulative risk and protective factors for gang affiliation ( $N=4131$ )

\begin{tabular}{|c|c|c|c|c|}
\hline \multirow[b]{2}{*}{ Variable } & \multirow[b]{2}{*}{ Total N (\%) } & \multicolumn{3}{|c|}{$\begin{array}{l}\text { Gang-affiliated students } \\
(\mathrm{N}=294)\end{array}$} \\
\hline & & N (\%) & Adjusted OR & $95 \% \mathrm{Cl}$ \\
\hline \multicolumn{5}{|c|}{ Cumulative risk index } \\
\hline 0 & $532(12.88)$ & $6(1.13)$ & Referent & \\
\hline 1 & $1002(24.26)$ & $33(3.29)$ & 2.63 & 0.99 to 7.00 \\
\hline 2 & $1075(26.02)$ & $59(5.49)$ & 4.37 & 1.64 to 11.60 \\
\hline 3 & $792(19.17)$ & $81(10.22)$ & 9.31 & 3.53 to 24.58 \\
\hline 4 & 493 (11.93) & $70(14.20)$ & 14.81 & 5.62 to 39.02 \\
\hline $5-6$ & $237(5.73)$ & 45 (18.99) & 21.51 & 7.89 to 58.64 \\
\hline \multicolumn{5}{|c|}{ Cumulative protective index } \\
\hline $0-3$ & 481 (11.64) & $125(25.99)$ & Referent & \\
\hline 4 & $727(17.60)$ & $69(9.50)$ & 0.81 & 0.63 to 1.05 \\
\hline 5 & $877(21.23)$ & $57(6.50)$ & 0.63 & 0.49 to 0.81 \\
\hline 6 & $793(19.20)$ & $32(4.04)$ & 0.44 & 0.31 to 0.61 \\
\hline 7 & $705(17.07)$ & $11(1.56)$ & 0.21 & 0.12 to 0.36 \\
\hline
\end{tabular}

Age, sex and race/ethnicity were controlled for in the models. 
Table 4 Predicted probabilities of gang affiliation for youth with various combinations of the significant protective factors and risk level

\begin{tabular}{lll}
\hline Protective factors & Low risk & High risk \\
\hline Neither parental monitoring nor coping skills & ${ }^{\mathrm{A}} 0.10$ & ${ }^{\mathrm{B}} 0.26$ \\
Parental monitoring alone & ${ }^{\mathrm{C}} 0.05$ & ${ }^{\mathrm{D}} 0.15$ \\
Coping skills alone & ${ }^{\mathrm{E}} 0.03$ & ${ }^{\mathrm{F}} 0.10$ \\
Both parental monitoring and coping skills & ${ }^{\mathrm{G}} 0.02$ & ${ }^{\mathrm{H}} 0.05$ \\
\hline
\end{tabular}

\begin{tabular}{lll}
\hline Comparisons of probabilities & \\
\hline Low risk & High risk & High risk $\times$ Low risk \\
\hline $\mathrm{C} \times \mathrm{A}$ & $\mathrm{D} \times \mathrm{B}^{* *}$ & $\mathrm{H} \times \mathrm{A}^{*}$ \\
$\mathrm{E} \times \mathrm{A}^{* *}$ & $\mathrm{~F} \times \mathrm{B}^{* *}$ & \\
$\mathrm{G} \times \mathrm{A}^{* *}$ & $\mathrm{H} \times \mathrm{B}^{* *}$ &
\end{tabular}

Low risk $=0-2$ risk factors. High risk $=3-6$ risk factors. To compare the predicted probabilities, Fisher's exact tests were used with a Bonferroni correction for multiple comparisons.

${ }^{*} \mathrm{p}<0.05,{ }^{* *} \mathrm{p}<0.01$.

affiliation by reducing the possibility for positive social connections and increasing opportunities for delinquent peer associations. Furthermore, the reciprocal relationship is also thought to exist where gang affiliation 'facilitates' an increase in these antisocial behaviours (eg, excessive substance abuse, more severe criminal behaviour) through peer pressure. ${ }^{11}$ Reducing the risk of initiating illicit substance use or delinquency early in preadolescence or adolescence might disrupt the initial trajectory towards gang affiliation or even potentially break current gangrelated connections that could further escalate these behaviours.

This study also showed the potential benefit of emphasising protective factors in prevention efforts. Two protective factors, youth's confidence in their coping skills and parental monitoring, were negatively associated with gang affiliation. Youths at high risk who had the two key protective factors had lower probabilities for gang affiliation than youths with neither of these factors at low risk. Also, youths at high risk with only one protective factor, confidence in their coping skills, had similar probabilities for gang affiliation as youths at low risk with neither factor. For youths in high-risk contexts, a focus on reducing risk factors may not be feasible in all situations due to the number of risk exposures and the difficulty in changing certain risk factors. Therefore, if it is not possible to reduce risk, adding one or two key protective factors may make youth at high risk appear similar to those at low risk. Other studies have documented a similar value in the use of protective factors against other forms of violence. ${ }^{21-23}$

\section{Limitations}

This study was subject to several limitations. First, the crosssectional nature of these data limited our ability to understand the causal ordering of the risk and protective factors and the outcome, gang affiliation. For instance, we were unable to determine whether confidence in coping with conflict prevented gang affiliation or whether youth developed poor coping strategies while affiliated with gangs. We also did not attempt to disentangle the complex relationships between gang affiliation, delinquency, alcohol use and drug use. Future prospective research would provide a better understanding of the relationship of these correlates. Second, surveying gang-affiliated youth in school may introduce a selection bias, and a non-response bias analysis was not done in this study. Further work that assesses whether these findings can be replicated in samples of youth who have dropped out of school, are truant or are adjudicated is important. Third, the survey did not define gang affiliation for respondents; therefore, gang affiliation in this study is likely to have a broad meaning. Past research has shown that using a more restrictive definition leads to more precision in distinguishing gangs from other youth groups. ${ }^{7}$ Finally, this study is limited to a high-risk population and the findings cannot, by this study design, be generalised to other populations.

\section{Prevention strategies}

This study has several important implications for prevention efforts. Since youth with both parental monitoring and coping skills had the lowest probability of gang affiliation, programmes that offer parent training that are focused on skills relevant to effectively monitoring children, in addition to helping youth develop strategies to cope with conflict, may be most beneficial for preventing gang affiliation. Several primary prevention programmes aimed at reducing delinquent behaviour have shown positive effects. ${ }^{24} 25$ Examples of evidence-based prevention programmes that address coping skills (ie, interpersonal skills, such as talking out disagreements, and intrapersonal skills, such as controlling anger) include the Promoting Alternative THinking Strategies (PATHS) curriculum and I Can Problem Solve. ${ }^{24} 25$ Examples of concurrent parent and child programmes targeting both coping skills and effective parenting include Strengthening Families Program, Fast Track, Prevention Treatment Program and Incredible Years. ${ }^{25}$ Of these programmes, only the Prevention Treatment Program showed reductions in gang affiliation. ${ }^{26}$ While the other programmes have not evaluated their impact on gang affiliation, given the shared aetiology of delinquency, drug and substance use, and gang affiliation, these programmes would likely be promising.

\section{Future directions}

Using a public health approach, we identified the potential of increasing a youth's confidence in their ability to cope with conflict and parental monitoring and reducing their delinquency, alcohol use and drug use to prevent gang affiliation. While studies that identify risk and protective factors represent one of the initial steps of the public health model, further work needs to be done to develop and evaluate primary prevention

\section{What is already known on the subject}

Risk factors for gang affiliation include friendship with delinquent peers, lack of parental monitoring, negative life events and positive attitudes towards delinquency or engaging in delinquency.

- Other risky behaviours associated with gang affiliation include alcohol use and drug use.

- The probability of gang affiliation increases as risk factors accumulate.

\section{What this study adds}

- This study showed the potential value of emphasising protective factors when assessing factors associated with gang affiliation.

- The findings suggest the potential benefit of increasing parental monitoring and coping skills and reducing delinquency, alcohol use and drug use to prevent gang affiliation. 
programmes that help reduce gang affiliation. Also, more work is needed to help disseminate programmes that can potentially prevent gang affiliation. Dissemination may be best accomplished with the inclusion of public health professionals in the planning and implementation of such programmes. These public health professionals may be able to assist in the necessary on-going collaboration with other sectors that traditionally work with gang-affiliated youth, such as criminal justice, to be most strategic about ways of combining community efforts to reduce gang affiliation.

Acknowledgements I wish to thank Dr J Logan for his contributions to this research.

Funding This study was supported by Centers for Disease Control and Prevention. Competing interests None.

Ethics approval Ethics approval was provided by Centers for Disease Control and Prevention (CDC) and ORC Macro International.

Contributors The Youth Violence Survey was developed by the CDC and was implemented in 2004 by contractors at ORC Macro International.

Provenance and peer review Not commissioned; externally peer reviewed.

Data sharing statement The data were obtained from the CDC's Youth Violence Survey.

\section{REFERENCES}

1. Pyrooz D. Structural covariates of gang homicide in large U.S. cities. J Res Crime Delinquen 2011:48:1-30

2. Hutson H, Anglin D, Kyriacou D, et al. The epidemic of gang-related homicides in Los Angeles County from 1979 through 1994. JAMA 1995;274:1031-6.

3. Thornberry TP, Lizotte AJ, Krohn MD, et al. Causes and consequences of delinquency: findings from the Rochester Youth Development Study. In: Thornberry TP, Krohn MD, eds. Taking Stock of Delinquency. New York: Kluwer Academic/ Plenum Publishers, 2003:11-46.

4. Gatti U, Tremblay RE, Vitaro F, et al. Youth gangs, delinquency and drug use: a test of the selection, facilitation, and enhancement hypotheses. J Child Psychol Psychiatry 2005;46:1178-90

5. Taylor T, Peterson D, Esbensen F, et al. Gang membership as a risk factor for adolescent violent victimization. J Res Crime Delinquen 2007:44:351-80.

6. Spano R, Freilich J, Bolland J. Gang membership, gun carrying, and employment: applying routine activities theory to explain violent victimization among inner city, minority youth living in extreme poverty. Justice Quarterly 2008;25:381-410.

7. Klein M, Maxson C. Street Gang Patterns and Policies. New York: Oxford University Press, 2006
8. Thornberry T. Membership in youth gangs and involvement in serious and violent offending. In: Loeber R, Farrington D, eds. Serious and Violent Offenders: Risk Factors and Successful Intervention. Thousand Oaks: Sage, 1998:147-66.

9. Thornberry T, Huizinga D, Loeber R. The causes and correlates studies: findings and policy implications. Juvenile Justice Bulletin 2004;9:3-19.

10. Hill K, Howell J, Hawkins J, et al. Childhood risk factors for adolescent gang membership: results from the Seattle social development project. J Res Crime Delinquen 1999;36:300-22.

11. Thornberry T. Gangs and Delinquency in Developmental Perspective. Cambridge: Cambridge University Press, 2003.

12. Thompson MP, Ho CH, Kingree JB. Prospective associations between delinquency and suicidal behaviors in a nationally representative sample. J Adolesc Health 2007:40:232-7.

13. Li X, Stanton B, Pack R, et al. Risk and protective factors associated with gang involvement among urban African American adolescents. Youth Soc 2002;34:172-94

14. Katz C, Fox A. Risk and protective factors associated with gang-involved youth in Trinidad and Tobago. Revista Panamericana de Salud Pública 2010;27:187-202.

15. Maxson C, Whitlock M, Klein M. Vulnerability to street gang membership: implications for practice. Soc Serv Rev 1998;72:70-91.

16. Sharkey J, Shekhtmeyster Z, Chavez-Lopez L, et al. The protective influence of gangs: can schools compensate? Aggression and Violent Behavior 2011;16:45-54

17. Swahn MH, Simon TR, Arias I, et al. Measuring sex differences in violence victimization and perpetration within date and same-sex peer relationships. J Interpers Violence 2008;23:1120-38.

18. Brofenbrenner U. The Ecology of Human Development. Cambridge: Harvard University Press, 1979

19. Logan J, Crosby A, Hamburger M. Suicidal ideation, friendships with delinquents, social and parental connectedness, and differential associations by sex: findings among a high-risk pre/early adolescent population. Crisis. Published Online First: 6 July 2011. doi:10.1027/0227-5910/a000091.

20. Esbensen F, Peterson D, Taylor T, et al. Youth Violence: Sex and Race Differences in Offending, Victimization, and Gang Membership. Philadelphia: Temple University Press, 2010.

21. Borowsky IW, Ireland M, Resnick MD. Adolescent suicide attempts: risk and protectors. Pediatrics 2001;107:485-93.

22. Borowsky IW, Hogan M, Ireland M. Adolescent sexual aggression: risk and protective factors. Pediatrics 1997; 100:E7.

23. Borowsky IW, Resnick MD, Ireland M, et al. Suicide attempts among American Indian and Alaska Native youth: risk and protective factors. Arch Pediatr Adolesc Med 1999;153:573-80.

24. Hahn R, Fuqua-Whitley D, Wethington $\mathrm{H}$, et al. The effectiveness of universal schoolbased programs for the prevention of violent and aggressive behavior: a report on recommendations of the Task Force on Community Preventive Services. MMWR Recomm Rep 2007:56:1-12.

25. Elliott DS. Blueprints for Violence Prevention (Vols. 1-11). Boulder: Center for the Study and Prevention of Violence, Institute of Behavioral Science, University of Colorado, 1997

26. McCord J, Tremblay RE, Vitaro F, et al. Boys' disruptive behaviour, school adjustment, and delinquency: the Montreal prevention experiment. Int J Behav Dev 1994;17:739-52

\section{Still undecided about using a cellphone while driving?}

For the past 4 years, California has banned drivers from using handheld cellphones. A study reveals that traffic deaths involving cellphones had fallen by $47 \%$. Deaths among drivers using hands-free phones dropped at a similar rate. The study examined deaths in the 2 years before and 2 years after the cellphone ban took effect, and found a similar drop in injuries. The explanation for the exceptional effectiveness of this law is that it was enforced: there were 460487 convictions in 2011 up 52\% from 2009. The Senator who proposed the law wants to increase the penalty from $\$ 20$ to $\$ 30$ for a first offense, but with court and other fees, the net cost, currently, is at least $\$ 159$. 